\title{
O MÉDICO E O CLIENTE
}

\author{
DR. ARNALDO AMADO FERREIRA \\ (Livre-docente e $1 .^{\circ}$ assistente de Medicina Legal da Faculdade de Medicina \\ da Universidade de São Paulo).
}

Dentre os deveres que norteiam a atuação do médico no seio da coletividade, salienta-se o das relaçôes com os clientes. Não há dúvida, o profissional da medicina tem deveres a cumprir, regras de moral a observar, porém, os que se utilisam de seus serviços, que reclamam a sua assistência, contraem obrigaçôes para com êle. Há, por assim dizer, reciprocidade de deveres entre o cliente e o médico. Tendo que se avir com indivíduos de todos os matizes sociais, dêsde os mais humildes aos mais abastados, encontrando na sua vida profissional toda uma gama de eduçação, deve o médico possuir qualidades de espírito e de "caráter, critério necessário para avaliar deficiencias, que o dinheiro nem sempre remedeia e que a gratidão tão poucas vezes recompensa. Em todas as camadas se the deparam bons e máus, entusiastas e depreciadores do seu trabalho, reconhecimentos e ingratidões, moeda muito humana, com que the pagam a dedicação, o esfôrç̧o, o desvêlo de noites inteiras de viǵ́lia, dias seguidos de cuidado com uma vida prestes a extinguir-se. Afronta perigo de contágio com o seu doente, expõe a vida, a cada instante, nas ocasiões de epídemias, na clínica privada, no laboratório, no campo de batalha, por toda a parte onde se faz necessário o seu trabalho e asua presença seja requesitada. Mas, que importa. A vida do médico é isso mesmo. É dever seu e precípuo aliviar as dores dos que sofrem, o divino trabalho cotidiano, finalidade e méta de toda uma vida cheia "de decepções, de muitas dores morais, de repetidos tormentos, de alegrias, mais das vezes, passageiras" e de todàs as profissões liberais é a Medicina a que mais sofre os embates do meio social, porque, considerando-a, em seu exercício, uma espécie de sacerdócio, os seus componentes não podem e nem devem lançar mãos de certos meios de auferir proventos, como soi acontecer com as demais profissões.

Ademais, "encarregado de velar pela vida de seu semelhante, o maior e precioso bem que recebe a cuidar, zeloso no cumprimento moral de seus deveres profissionais, o médico honesto, probo, escrupuloso, não deseja que a sua profissão se abaștarde, nem se torne mercadoria de baixo preço. Ao contrário, preocupa-se com enobrecê-la, prestigiá-la, exercê-lạ com retidão, afim de que o cliente se lhe entregue confiante, certó de que os seus males serão aliviados, 
os fatos de sua vida secreta guardados religiosamente, os conselhos que the der, ditados pela sinceridade e interêsse de vê-lo curado de seus, males e feliz. E preciso que se diga, a-pesar do materialismo imperante, da depreciação moral por que passam as profissões liberais, a Medicina não é, nunca foi e nem será comércio. Łé bem verdade, o médico, homem como qualquer outro, tem encargos de família, de representação, necessita viver e por isso trabalha. E dever seu cuidar dos que thes são caros, acobertá-los das necessidades materiais e, assim faz jús a seus honorários. Entanto, não abusará, não deve obrigar o seu cliente a despesas inuteis, não cobrará demasiado pelo serviço que the prestar. Fará um justo preço, consoante o trabalho realizádo, condições de poșse de cada um, sem se aproveitar e nem fazer roça ao cliente.

É evidente, posto não seja a regra, o cliente saiba corresponder; compreender e aquilatar o esfôrço, o desvêlo do médico e the pagar com pontualidade os serviços que recebera em hora aflitiva de sua vida.

O materialismo de hoje, a facilidade de se ganhar dinheiro, de qualquer modo, proporciona falta de escrúpulo a certos profissionais, cuja formação moral mutio fica a desejar. Mas, em todas as profissõeis há de tudo. Por certo, não será pela conduta dos que assim procedem, que o público julgará o médico. São excepções. A falta de solidariedade humana, o excesso de individualismo é o que provoca o desagregamento dos sentimentos altruistas, trazendo consigo a ganância e o embotamento das nobres qualidades do indivíduo. A maioria dos médicos, todavia, vêm na sua nobre profissão uma espécie de sacerdócio, que se assenta em rigorósos preceitos de moral e, por isso, traça para si, regras de rígido procedimento, para com os clientes, diretrizes que se inscrevem nos deveres da paciência, da dedicação, da caridade, da discreção e da prudência, de uma sã conciência no exercício de sua profissão.

Bem sabe o cliente que não deve exigir do médico mais que a sua profissão the pơde dar. A Medicina não é ciência ainda, completamente, propriamente, positiva. "A-pesar-de suas conquistas e de suas descobertas, não sé libertou do maravilhoso. $E$ é por isso que a sua sombra medram ainda charlatães e curandeiros Há muitos males que se curam e outros tantos que se não curam. Daí, o médico, digno dêste nome, nunca se comprometer a curar o seu cliente em prazo fixo, predeterminado, mas, sim, tratá-lo com desvêlo, carinho, abnegação. E isso, porque, as doenças variam em suas manifestações, consoante o organismo em que evolvem; depois, também, o que o médico tem diante de si é o doente, o indivíduo, onde os fatores cosstitucionaes, hereditários e adquiridos, mesológicos, fazem variar as condições da resistência orgânica e a ação dos medicamentos empregados, reservando grandes e às vezes surpresas bem desagradaveis para os pouco prudentes. $O$ médico deve ter algo de psicólogo, impôr-se pelo seu saber, pelas suas maneiras de homem educado, porquê captará a simpatia e a confiança do dónte, da fa- 
mília do seu cliente e impedirá que pessoas das relações do doente aconselhem certos medicamentios de que se serviram em caso parecido, isto aliás feito na melhor das intençộes; mas que não se relacionam com o caso em apreço. Mau é êsse proceder de certas pessoas, porque pode prejudicar ao doente e as pessoas da família ficam a pensar numa atuação descuidosa do médico. Nêstes casos, o médico deve revestir-se de dobrada paciência para com o doente, para com as pessoas da família e, sobretudó, para com a própria doença. Deve considerar que de "médico e de louco todo o mundo tem um pouco", conforme o brocado. Há enfermos que desejam conhecer a ação do medicamento prescrito, a sua composição, vivem a lêr bulas de quantos preparados lhes caem às mãos, opinam sôbre o tratamento, pedem pormenores de seus males, etc. E' comum, pessoas da família, inte-ressadas pelo doente, apresentarem sugestões ao tratamento estabelecido, aconselhando o uso de determinado remédio, muito apropriado ao caso, fazem ao médico perguntas reiteradas, indiscretas, procurando inconcientemente que êle revele fatos de natureza secreta e que deve guardar. Mesmo, em meio culto, sofre o profissional da medicina da bisbilhotice de certos indivíduos havidos como experientes, entendidos e mais, dizemos, imprudentes. O médico não se agastará com isso. E' 'da profissão. Com delicadeza dirá o que convem, sem melindrar ao doente e ao meio. O médico, por sem dúvida, é tão interessado pella saúde, pella vidà do doente, quanto as pessoas de sua família. Estas devem acatar e ouvir as suas determinações, respeitálas; não dar ouvido as visitas, aos visinhos cujo parente se curou com. o. emprêgo de certo medicamento, prescrito por excelente doutor de suas relações. Há doente e não doenças e essas, às vezes, de evolução demorada, caprichosa, daí, naturalmente, o cliente ser paciente e confiar na atuação de seu médico assistente. Um verdadeiro médico nunca abusará das posses de seu cliente e nem de sua confiança. Chamando-o, o cliente firma com êle um contrato tácito, de ordem moral, sem fórmulas escritas. Não pode o cliente despachá-lo, escusar o seu serviço sem uma satisfação e explicação prévias. Se o doente vir que o médico, no seu pensar, não correspondeu ao que desejava, será leal, franco, irá a êle e lhe esporá as dúvidas e êste usará de franqueza para com o cliente. 'E' reprovavel, o que comumente acontece, mesme entre gente que se diz educada e culta, apelar para novo médico sem ciência do médico assistente. Nenhum médico deve atender a chamados nestas condições, a menos que se trate de casos de urgência, ou por não se encontrar o médico assistente no momento. Em caso contrário, o facultativo que assim proceder infringirá os preceitos da boa ética.

O profissional da medicina será ponderado, cuidadoso em anunciar a.sua especialidade e na maneira de oferecer os seus serviços profissionais, para evitar que o confundam com os falsos médicos, que tudo curam, mesmo as doenças incuraveis, que possuem os maiores e melhores aparelhos para todas as especies de diagnósticos e tratamentos. Não se emparelhe com os curandeiros e charlatães, com 
êsses mercadores do templo da Medicina, com os que, em chegando à casa do cliente, depreciam o colega que lá estivera, deitam pela janela os medicamentos prescritos. Cuidado com os anuncios espalhafatosos, deprimentes, luminosos, de esculápios de longa experiencia e sempre recém-chegados do estrangeiro; tome tento com os agencadores e comercialisantes da profissão.

Há clientes que se queixarn de que os médicos não lhes atendem os chamados com presteza. O médico é livre de atender a quem quizer, porém essa liberdade não é absoluta, é condicionada à certas regras. Se anuncia nos jornais, tem consultório, placa à porta, exerce à clínica $e$, sobretudo, se único na localidade, não pode deixar de atender ao chamado do cliente. "Mais do que moral, a lei coage o médico atender o doente, a cumprir pois o seu dever, realizando, aliás, as prerogativas de um monopólio, de verdadeiro previlégio". Muitas pessoas têm o mau costume de fazer consultas pelo telefone, no bonde, por cartas, pelos jornais. Examinando-se atenta e cuidadosamente o doente, empregando-se todos os recursos que a ciência recomenda para o esclarecimento do caso em apreço, muita vez não șe chega ao diagnóstico! Como, em ausência, à distância, com informações incompletas, nem sempre verídicas, porque fornecidas por inexperientes, poder-se-à fazê-lo? 'A Medicina não é ciência de adivinhação. Excusado é dizer-se que o médico deve ser dedicado ao doente, seja rico ou pobre, tenha ou não certeza de remuneração. "Será abnegado, irá mesmo ao sacrifício". Quantos não tombaram no cumprimento do dever e esquecidos permanecem da memória dos homens.

No trato com o seu doente, rico ou pobre, na clínica civil ou hospitalar, sempre vê nele o semelhante que sofre, que necessita dos seus conhecimentos, afim de se curar, de alieiar-se de seus males, das dores físicas e morais de que padece. Especial cuidado merecerão do médico os doentes hospitalisados, os indigentes, os desfavorecidos de recursos. Tornam-se dignos do seu carinho, desvêlo e gratidão. "Nunca sejam a doença e a posição social uma inferioridade de quem quer que seja aos olhos do médico", mas antes o atrativo seguro às manifestações dos sentimentos de humanidade, de um coração bem formado. Tenha o médico, nas suas palavras, nos seus atos, "a doçura necessária par consolar, aliviar e curar. Quem sofre conta com a piedade dos que exercem a ciência e a arte de curar"

O médico abster-se-à de discutir política, religião com o cliente e mesmo evitará incutir no seu espirito sua crença religiosa e as suas convicções políticas. Respeitará, nêste particular as convicções do seu doente, lembrando-se sempre o que o leva a sua cabeceira é outra finalidade. Quem procura o médico, num caso de necessidade, alheiase a tais questões. E' o profissional da medicina um trabalhador intelectual que se sacrifica diariamente pelo bem de outrem, auferindo do seu trabalho o necessário para o seu sustento e dos seus. A medicina não é profissão que permita com facilidade fazer fortuna. Raros são os que conseguem acumulá-la. São tão poucos os aquinhoados da 
sorte e poderião apontar-se a dệdo. E' justo, pois, vivendo do 'seu trabalho honesto, receba a remuneração do serviço prestado ao cliente. Como se vê, é profissão espinhosa a Medicina, dificil de exercida, que há milenios, Hipocrates, havido como o seu. fundador, numa máxima que resume todo o trabalho do médico, todas as dificuldades que encontra, todas as ingratidões e benemerências que recebe, numa vida dedicada ao bem de outrem, cheia de estudos, abrolhos, disse: que à sua "brevidade se contrapunha" a vastidão de conhecimento exigidos dêle, a passagem fugace da ocasião,'a autoridade tão enganosa da experiencia e a forçosa vacilação do espirito humano" 